\title{
How Would the Trackless Tram System and Public-Private Partnership (PPP) Apply to Bulawayo?
}

\author{
Vinnet Ndlovu, Peter Newman \\ Curtin University Sustainability Policy (CUSP) Institute, School of Design and the Built Environment, Curtin University, \\ Perth, Australia \\ Email: vinnet.ndlovu@postgrad.curtin.edu.au
}

How to cite this paper: Ndlovu, V., \& Newman, P. (2021). How Would the Trackless Tram System and Public-Private Partnership (PPP) Apply to Bulawayo? Current Urban Studies, 9, 17-30.

https://doi.org/10.4236/cus.2021.91002

Received: December 3, 2020

Accepted: January 30, 2021

Published: February 2, 2021

Copyright $\odot 2021$ by author(s) and Scientific Research Publishing Inc. This work is licensed under the Creative Commons Attribution International License (CC BY 4.0).

http://creativecommons.org/licenses/by/4.0/

\begin{abstract}
The City of Bulawayo urgently needs to rebuild its dilapidated infrastructure and stimulate its economic activities. A Public-Private Partnership funding mechanism could enable the implementation of Trackless Trams on its corridors bringing mobility, a new solar power system and other multiple economic and social benefits, especially demonstrating the intention of Bulawayo to leapfrog into a 21st century future. This study designs a PPP model referred to as a Three Multifaceted PPP Model (TMPM) that will enable the implementation of the Trackless Tram project in Bulawayo. The TMPM model is composed of three layers of players each required to structure a separate PPP arrangement. The city council would lead the first layer responsible for road construction. The real estate developers would lead the second layer and be responsible for constructing station precincts especially the construction of a solar-based Transit Mall. The Trackless Tram consortium and public transport agency will manage the third layer that provides and operates the trams. The split of the project into three layers should enable its quicker delivery by lowering capital risk through spreading it over a number of players. Climate finance could be tapped. This model should be replicable to other developing cities.
\end{abstract}

\section{Keywords}

Trackless Tram System, Light Rail-Light Metro Transit, Public-Private Partnership, Three Multifaceted PPP Model, Bankability Assessment, Capability Evaluation

\section{Introduction}

The City of Bulawayo was not spared from the effects of Zimbabwe's two dec- 
ades of economic meltdown. That episode has left the city's infrastructure at the verge of almost total collapse (City of Bulawayo, 2020b; Ndlovu et al., 2020). The once envy of many cities in Africa in terms of its robust and well-managed infrastructure, it is now one of the poorest cities in Africa. Not only have the road and water infrastructure almost totally collapsed, the city has experienced a major episode of deindustrialisation (Zaaijer, 1998). According to the information from its latest strategy document (City of Bulawayo, 2020a: p. 11), the city's industry is operating at less than $30 \%$ of its capacity. Though the structure of its industry and urban system is still in existence, Bulawayo urgently needs to rebuild most of its public infrastructure especially its road network. However, the city is facing financial challenges and has few resources to rehabilitate its critically needed public infrastructure and reactivate its economic activities. The city will need to show it wants to become a major urban centre in 21st century to provide a good African life and economic activity. To do this it will need to explore the possibility of adopting technologies that could ideally leapfrog it technologically into a city of the future (Ndlovu \& Newman, 2020). Trackless Tram Systems (TTS) have the potential to do just that for the City of Bulawayo given the city's current physical situation and socioeconomic settings. The adoption of this technology will have a profound effect on the psyche of the local and business communities, and promote the perception of Bulawayo as a city that is geared to be a leader in innovation (Ndlovu \& Newman, 2020a; Ndlovu \& Newman, 2020; Ndlovu et al., 2020).

Besides the leapfrogging capabilities, the TTS will simultaneously give the city the impetus and opportunity to start the reconstruction of its infrastructure, especially its roads that currently are in a dire state. It will also give the city a chance to move into solar energy as part of the recharge system for the electric (battery-based) TTS and provide new urban regeneration opportunities from investment around the new stations. As discussed by Ndlovu et al. (2020) the TTS should enhance and stimulate the City of Bulawayo's economic regeneration agenda.

However, there is a need to create a way of enabling the TTS to be funded as the City of Bulawayo is not able to access such project funding with its current financial challenges (Ndlovu \& Newman, 2020b). Thus a Public-Private Partnership funding mechanism has been suggested to be the best strategy for Bulawayo to build this critically needed public infrastructure project. The city needs to reach out to the private sector who is able to fund such major public infrastructure as expounded by the Secretary General of the International Telecommunication Union (ITU) (2014) who proposed that the private sector has the capacity to fund such public projects through Private-Public Partnerships (PPP) arrangements.

PPP's can also enable other skills to be brought into the project through expertise in such 21st century technology as TTS, solar energy and smart systems that support these leapfrog projects. The Trackless Tram System could be im- 
plemented through a mechanism such as the entrepreneur rail model, the concept discussed in detail by Newman, Davies-Slate, et al. (2018). To reconstruct and regenerate its public infrastructure by adopting game changing technologies like TTS the City of Bulawayo will have to engage the private sector through a win-win PPP arrangement that carefully works out the best way to achieve the broader public goals as well as enabling the innovation and funding to create a successful project financially.

The PPP model can also enable urban regeneration to be linked to the project and with the TTS enabling value increases to the land around stations, then the project has a sound basis in land development to enable it to attract good investors to the city. There is no doubt that the private sector will be crucial to the city's strategy to regenerate its corridors and resuscitate its economic activities (City of Bulawayo, 2020a, 2020b; Newman et al., 2018). The City of Bulawayo is already geared towards allowing the private sector to lead in regards to the reconstruction of its public infrastructure and revitalisation of its economic activities (City of Bulawayo, 2020a: p. 24). Therefore, a well-constructed PPP arrangement could see the city implement its TTS project, its energy and even its water infrastructure projects that will help it to reindustrialise again. This study will design a PPP model that should enable the implementation of a TTS on the City of Bulawayo, creating transit activated corridors (TACs) identified in the study by Ndlovu \& Newman (2020a).

In order to design an ideal PPP arrangement, this paper will endeavour to address the research question "How would the Leapfrog innovation of a Trackless Tram System and PPP's apply to Bulawayo?", through examining literature on PPP's and applying this to the financial and management capability of the City of Bulawayo. The paper seeks to show how the City of Bulawayo could build a new culture of creativity and innovativeness going forward that can help it to be a future leader in the utilisation of leapfrog technologies such as TTS.

\section{Methodology}

The study will initially conduct a literature review to ascertain the fundamentals necessary for formulating a successful PPP with this kind of infrastructure, known as mid-tier transit, or as The World Bank calls it "light rail-light metro transit" (LRMT) PPP (Mandri-Perrott \& Menzies, 2010). This World Bank Report will be explored extensively as it has set the scene for all the rest of the literature. Informed by this the study will formulate the bankability evaluation and capability assessment frameworks for Bulawayo's TTS project. With the understanding of the relevant fundamentals that are ideal for a functional LRMT PPP, the study will then structure an ideal PPP arrangement/model for the City of Bulawayo's TTS project. The study will then further discuss the results of the assessment and evaluation frameworks and the proposed Bulawayo TTS PPP model. Figure 1 gives an overview of this study's structure and methodology. 


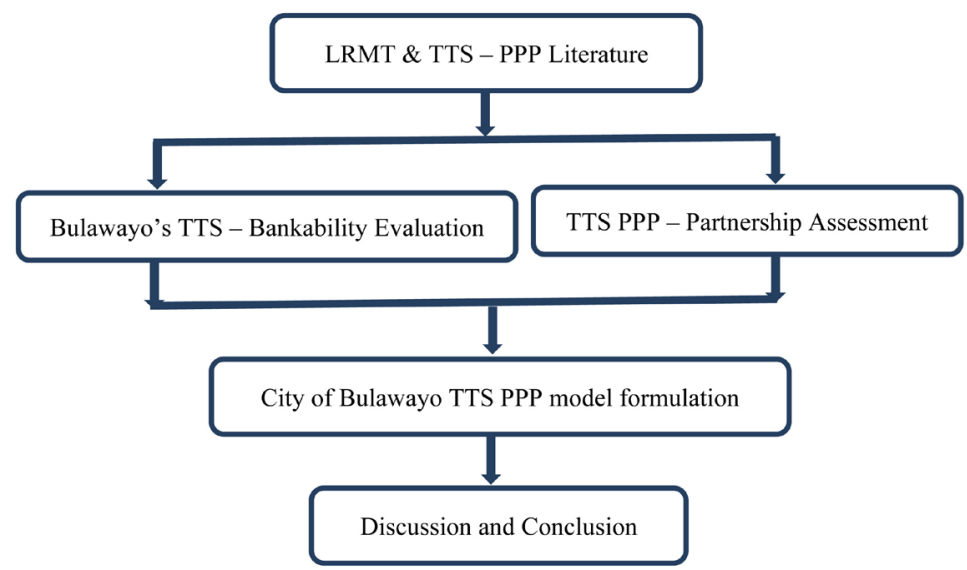

Figure 1. Study's structure and methodology.

\section{City of Bulawayo's Future with PPPs}

Bulawayo has a good record of successfully implementing various funding mechanisms for its construction and urban development projects. It was the first city in Zimbabwe to adopt the Public-Private Partnership (PPP) arrangement to build low-cost houses for its residents. The Cowdrey Park suburb was built through a PPP arrangement between a Zimbabwe-Malaysia Holdings company to construct up to 15,000 housing units (Mbiba Beacon \& Ndubiwa Michael, 2008). Given its robust governance and forward-looking reputation, Bulawayo could implement a similar strategy adopted by Colombia's City of Bogota during the short stint of its mayor Antanas Mockus Sivickas (Willoughby, 2013). Bogota achieved its implementation through PPPs especially its transit-oriented development projects. During his short tenure, Antanas Mockus Sivickas undertook various PPP projects structured in a way that emphasised the public sector (City of Bogota) to lead in the construction of stations and infrastructure, while the private sector was enabled to lead in the provision of buses and their operations. This PPP arrangement led to the City of Bogota establishing its first BRT project. A similar type of PPP arrangement could suit the City of Bulawayo and enable it to implement its Trackless Trams project. As elaborated by Meidutē \& Paliulis (2011), PPP arrangements are very attractive especially during economic crises, for they are likely to sustain or stimulate the economy, hence allowing the public sector to allocate scarce funds to other crucial areas. This is ideally suited to the City of Bulawayo as it has been in a financial crisis for some time and is looking for mechanisms that will stimulate and resuscitate its economy.

To avoid falling into the Lithuanians' PPP pitfalls identified by Meidutē \& $\mathrm{Pa}-$ liulis (2011), there is a need for the City of Bulawayo to evaluate its readiness to adopt the PPP funding mechanism and to manage the process. The council authorities will need to deal with the issues that might surround the adoption of the PPP approach as elaborated by Bhoroma (2020). The methodology and results of determining what will be needed for the council to do will therefore be elaborated next. 


\section{Public-Private Partnership in Light Rail Metro Transit and Trackless Trams}

According to Mandri-Perrott \& Menzies (2010: p. 9) interest is growing in the use of light rail-light metro transit (LRMT) this interest has also seen the increase in the usage of public-private partnerships (PPPs) to support these initiatives. This study will assume TTS is classified as a type of LRMT as it has similar LRMT attributes or metrics portrayed by Mandri-Perrott \& Menzies (2010: p. 17) and Newman, Mouritz, et al. (2018: p. 85). Mandri-Perrott \& Menzies (2010) postulate that ever-expanding urbanisation (urban sprawl) has driven cities around the globe to look for better ways to improve their transportation services. LRMT if implemented correctly can help resolve this challenge for any city but especially fast growing ones like in the developing world. Such cities, not only can resolve their transportation issues, but they are also environmental friendly and socially responsible technologies that will reduce urban sprawl as well as vehicular carbon emissions (p. 11). However, to achieve efficient transportation systems through the introduction of the LRMT or TTS requires a well thought-out and strategic approach of implementation. Hence the postulation by Mandri-Perrott \& Menzies (2010) that "designing properly integrated, intelligently planned, and well operated public transportation networks typically requires a centralized transportation or transit authority" (p. 14). As discussed by Mandri-Perrott \& Menzies (2010), LRMT projects have very high capital expenditure investment, and they usually do not collect enough fares revenues to cover their operating costs. However, as already elaborated Trackless Trams (TTS) do provide all the benefits associated with LRMT, and are considerably cheaper to implement than the traditional LRMT and have the potential to raise funds through urban development to help pay for the infrastructure (Newman et al., 2018: p. 84).

According to Mandri-Perrott \& Menzies (2010) one of the four fundamental factors that govern a good PPP framework is a well prepared PPP model. The purpose of this study is to structure an optimal PPP model that will enable the delivery of Bulawayo's TTS project publicised by Kazunga (2019) and discussed by Ndlovu \& Newman (2020a). Such high profile projects as the adoption of TTS and LMRT will require the support of not just the local government but also the central government to enhance the success of such initiatives. At the same time the PPP will need to go beyond transport issues and involve urban development processes and outcomes that can be fully integrated into the project. According to Mandri-Perrott \& Menzies (2010), “an integral part of the government's transport policy will require specific support for the procurement of a developer to undertake all or some parts of the LRMT scheme" (p. 46). The integration of transport and land use is guaranteed by enabling such a process.

When it comes to designing a PPP model or agreement, each one depends on the specific context though similar principles can be applied in all cases. For 
example an underlying principle is that a good PPP arrangement is one that allocates and matches risks and rewards accurately between the project sponsors and the developers; however, this will vary considerably in different contexts in how the allocations are worked out.

The standard PP model was developed in the 1970's but in transport they were much slower to adopt the model. As transport has been dominated by governments the early transport PPP's were much more rigid approach with a high government element. For example, below are the common PPP base models discussed by Colin Buchanan and Partners (2002) with regards to the common transport projects across Europe:

- Management contract

- Gross-cost contract

- Net-cost contract, more commonly known as a lease

- Net-cost contract with investment (NCCI), more commonly known as the concession, build-operate transfer (BOT) form or finance-design-build-operate maintain (FDBOM)

According to Colin Buchanan and Partners (2002) the most common and appropriate PPP model for a transport project is to provide depots and other relevant infrastructure through a Build, Own and Transfer (BOT) partnership. This arrangement is usually for a long contract spanning a period of 20 to 30 years to allow the investors to recover their investment costs. The BOT model falls under an arrangement commonly known as the "unified approach" to the PPP agreement. It is now seen as being too rigid by the World Bank as set out by Mandri-Perrott \& Menzies (2010). This study needs much more flexibility in how it approaches the partnerships needed to deliver the project in Bulawayo. What is needed in Bulawayo and probably any developing city, will be to utilise the alternative approach known as the "layering approach". In this approach, "the project may be split among two or more separate PPP agreements addressing the construction of infrastructure, the procurement of rolling stock, and the operation of the system" as elaborated by Mandri-Perrott \& Menzies (2010: p. 64). The very successful Docklands Light Railway (DLR) PPP uses this approach with separate PPP agreements for different components of its light rail services.

Countries with significant perceived risks do find it hard to attract private sector investments, because their weighted cost of capital to undertake business initiatives will have to factor in a very high-risk return, making the cost of capital extremely high. Capital grants and project subsidies might have to be availed to the developers to undertake such projects as the TTS for Bulawayo a city located in a country perceived as very risky. According to Dauskardt \& Ganguly (2020):

"Globally, governments have had to contribute to the financing of infrastructure projects implemented through PPPs, across emerging and developed PPP markets. The public contribution comes in various forms, including construction grants, viability gap grants, availability payments, eq- 
uity investments, concessional loans, and operational subsidy etc." (p. 6).

As already hinted by Mandri-Perrott \& Menzies (2010), most LRMT's fare income are often insufficient to cover the operating and maintenance costs and the major investment costs of new construction, renewal, and renovation, hence the need for the subsidy and capital grants from the government. However, they still maintain that private participation is still possible even if fares do not cover costs (p. 96). This highlights the need to structure PPP models that should avoid asset sweating. As outlined below there will be less risk in the Bulawayo TTS as first the post Covid era has much lower global interest rates than when the above literature was being written, and second the project seeks to build in land development as a way to make the project less risky and more able to create profits than just fare box models. This approach is explained by The World Bank as the "value capture" approach and is very common in Asia and some emerging cities but less so in Europe and America (Suzuki et al., 2015). One other component of the PPP for a TTS would be needed and would appear to fit the situation in $\mathrm{Bu}$ lawayo is that of providing solar electricity to any buildings associated with the station precincts; this would be to bring a 21st century and affordable power system to the TTS corridor and to enable the trackless trams to be recharged at particular stations.

As posited by Dauskardt \& Ganguly (2020), “PPPs deliver value for money for governments by leveraging private innovation to provide public services more efficiently" (p. 5). African countries, doubly so Zimbabwe and unavoidably Bulawayo, are struggling and need a new approach to development that can bring funding, expertise to match the local knowledge and expertise. PPP's around a TTS appear to be a possibility as "PPPs can be an alternative source of finance for infrastructure investments in African countries, while potentially also delivering higher quality and efficiency in public assets and services" (Dauskardt \& Ganguly, 2020: p. 5). However, the next section will drill down to try and see if the "layering approach" could work in Bulawayo.

\section{Evaluation of Bulawayo TTS Project's Bankability and Partnership Assessment}

The main factors that determine whether major projects such as the TTS or LRMT succeed is their bankability, and their developers' capabilities. According to Mandri-Perrott \& Menzies (2010), the term bankability goes beyond just the usual assumed financial analysis. Below are the four broad criteria identified by Mandri-Perrott \& Menzies (2010: p. 11) that should constitute a true bankability assessment:

- Creditworthiness

- Legal viability

- Economic viability

- Technical feasibility.

The introduction of TTS into the corridors of the City of Bulawayo will largely 
entail three major components of the project's milestones/undertakings:

1) Road reconstruction

2) Station precincts' and the surrounding neighbourhood construction

3) Provision and operation of the rolling stock.

The above undertakings do confirm this to be a major and complex project that will require different players with different capabilities. Since bankability and capability are the main determinants for the deliverability and implementation for most PPP projects, this study will utilise the four broad criteria identified by Mandri-Perrott \& Menzies (2010: p. 11) to formulate a framework to evaluate the bankability of each of the three TTS project's undertakings identified above. After the overview Bankability Assessment of the above project's undertakings, the study will further conduct an evaluation of the partners/players' (developers) capability with a focus on their intrinsic comparative advantages. The assessment of the players will entail testing and identifying each player's capabilities to deliver the projects' undertaking of components/milestones identified above. These results will inform the study on how to structure an ideal PPP model using the case study of the TTS project for the City of Bulawayo.

\subsection{TTS' Bankability Assessment}

Bankability Assessment of TTS project for the City of Bulawayo is set out in Table 1 using the framework developed by The World Bank (Mandri-Perrott \& Menzies (2010). The simple assessments given are based on the previous academic research on this topic (Ndlovu \& Newman, 2020a; Ndlovu \& Newman, 2020; Ndlovu et al., 2020) as well as local knowledge (Newman et al., 2018).

\subsection{Evaluation of PPP Partner Capabilities and Comparative Advantage}

TTS players' capability and comparative advantage evaluation are set out in Table 2 also using the framework developed by The World Bank (Mandri-Perrott \& Menzies (2010).

\subsection{The Three Multifaceted PPP Model}

Based upon the results of the Bankability Assessment of the Bulawayo TTS project and the evaluation of the capability of the potential partners in this PPP arrangement through a Partner Capability, this study now recommends an ideal PPP model supported by the metrics of the evaluation and assessment frameworks. This study recommends the City of Bulawayo adopt a TTS PPP model depicted in Figure 2. This has a high likelihood to enable the implementation of the Trackless Trams project on Bulawayo's major corridors. This model is structured around three layers of players/developers that will constitute three different PPP arrangements that would be integrated finally into one package for delivery. The study refers to this proposed PPP structure/model as the Three 


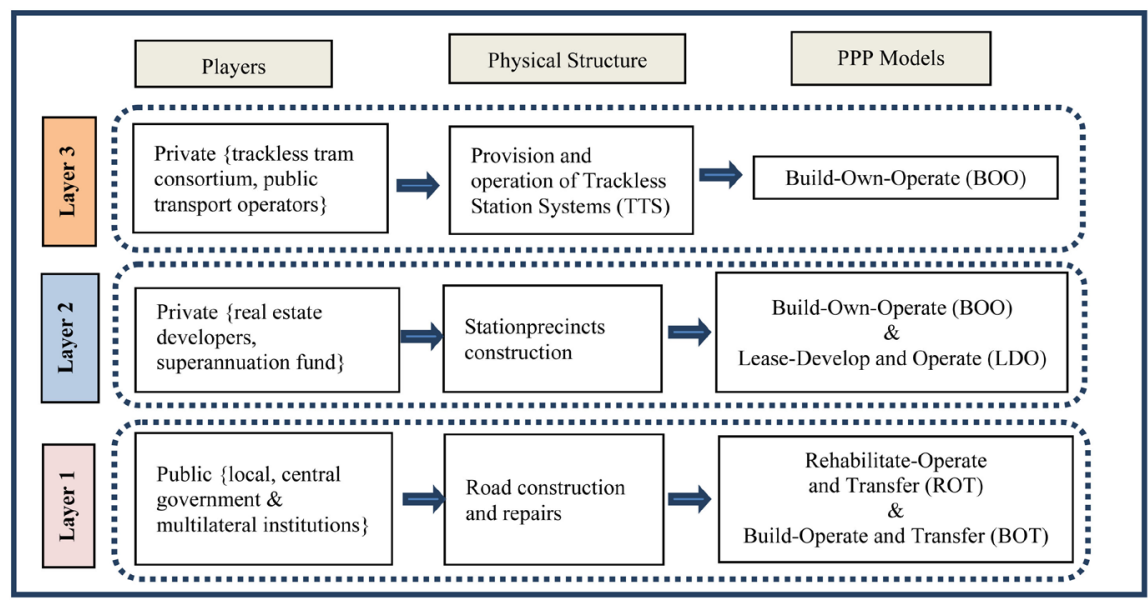

Figure 2. The Three Multifaceted PPP Model (TMPM).

Table 1. City of Bulawayo TTS project bankability assessment.

\begin{tabular}{|c|c|c|c|c|c|}
\hline \multicolumn{6}{|c|}{ Bankability assessment of TTS project for the City of Bulawayo } \\
\hline \multirow{2}{*}{$\begin{array}{l}\text { TTS project's major } \\
\text { components/milestones }\end{array}$} & \multicolumn{4}{|c|}{ Variables } & \multirow[b]{2}{*}{ Assessment } \\
\hline & Demand/Urgency & $\begin{array}{c}\text { Legal } \\
\text { viability }\end{array}$ & $\begin{array}{l}\text { Economic } \\
\text { viability }\end{array}$ & $\begin{array}{l}\text { Technical } \\
\text { feasibility }\end{array}$ & \\
\hline Road construction* & 5 & 4 & 4 & 5 & 4.5 \\
\hline $\begin{array}{l}\text { Trams station precincts } \\
\text { construction }\end{array}$ & 5 & 4 & 5 & 5 & 4.8 \\
\hline $\begin{array}{l}\text { Rolling stock acquisition } \\
\text { and operations }\end{array}$ & 5 & 4 & 3 & 4 & 4.0 \\
\hline ASSESSMENT & 5 & 4 & 4 & 5 & 4.4 \\
\hline \multicolumn{6}{|c|}{ Legends } \\
\hline \multicolumn{2}{|c|}{ Metrics } & \multicolumn{4}{|c|}{ Values } \\
\hline \multicolumn{2}{|l|}{ High } & \multicolumn{4}{|c|}{5} \\
\hline \multicolumn{2}{|c|}{ Low high } & \multicolumn{4}{|c|}{4} \\
\hline \multicolumn{2}{|c|}{ Moderate } & \multicolumn{4}{|c|}{3} \\
\hline \multicolumn{2}{|c|}{ Low moderate } & \multicolumn{4}{|c|}{2} \\
\hline \multicolumn{2}{|l|}{ Low } & \multicolumn{4}{|c|}{1} \\
\hline
\end{tabular}

Metrics highlights: ${ }^{*}$ According to the report of study for the City of Bulawayo (p. 258) approximately $40 \%$ of the city's roads are in poor and unaccountable state. This makes it a top priority for the city to resurface and reconstruct its roads. The urgency for this task is high and the technical ability to undertake this task by the council is high. ${ }^{*}$ Currently the waiting list for affordable houses for the city is standing at 115,000 according to the City of Bulawayo (2020b: p. 128). The proposal to introduce TTS on the corridors with the potential of having station precincts that can also cater for residential property development through private developers is a great opportunity for the city and that can resolve its huge housing waiting list. Thus, there is huge demand for affordable housing and the private sector have the capital and expertise to undertake this task efficiently and quicker. Developers are available with plans to pursue such projects and in conversation have expressed interest in how a PPP could enable a land development-based approach with an emphasis on solar electric systems for the housing as well as to recharge the TTS. ${ }^{* * *}$ Bulawayo is having some significant issues with its public transport systems evidenced by the sudden reintroduction of the State bus company, Zimbabwe United People Company Omnibus (ZUPCO). This alternative public transport system has run down the already poor city's public transport system. An alternative sustainable transport system is urgently required to catalyse the city's corridors' renewal and regeneration capacity. Trackless trams have the potential and capability to enable corridor renewals and regeneration (Ndlovu \& Newman, 2020; Newman et al., 2019). 
Table 2. City of Bulawayo PPP partners' capabilities evaluation.

\begin{tabular}{|c|c|c|c|}
\hline \multirow[b]{2}{*}{ TTS Partners/players } & \multicolumn{3}{|c|}{ Project milestones } \\
\hline & $\begin{array}{c}\text { Road } \\
\text { construction }\end{array}$ & $\begin{array}{l}\text { Trams station } \\
\text { precincts } \\
\text { construction }\end{array}$ & $\begin{array}{l}\text { Rolling stock } \\
\text { acquisition and } \\
\text { operations }\end{array}$ \\
\hline The City of Bulawayo* & 3 & 2 & 2 \\
\hline Real estate developers ${ }^{\star *}$ & 2 & 3 & 1 \\
\hline $\begin{array}{l}\text { Transport operators } \\
\text { (TTS Consortium) }^{* * *}\end{array}$ & 1 & 2 & 3 \\
\hline \multicolumn{4}{|c|}{ Legends (Comparative Advantage) } \\
\hline \multicolumn{4}{|c|}{ Metrics } \\
\hline \multicolumn{4}{|c|}{ High } \\
\hline \multicolumn{4}{|c|}{ Medium } \\
\hline \multicolumn{4}{|c|}{ Low } \\
\hline
\end{tabular}

Metrics highlights: ${ }^{\star}$ Given its over 100 hundred years of experience and background in road construction, the City of Bulawayo have the comparative advantage in undertaking these tasks compared to other partners. Therefore, a partnership arrangement will do well in parcelling the risk of road construction to the City of Bulawayo as it stands well in managing this kind of risk in the project. ${ }^{* *}$ Real estate developers' core business is to develop commercial and residential properties (including station precincts and their surroundings), thus they should have some comparative advantage in managing such tasks efficiently compared to the other developers/partners in this potential PPP arrangement. This is a good opportunity for the City of Bulawayo to untangle itself from the old traditional culture of providing housing for its low-income residents and regulate to enable the developments around stations to include a certain proportion of affordable housing. The PPP would also enable other commercial and residential markets to be met along the TTS corridor as a way of helping to fund the TTS as part of the PPP. This must also involve the State Ministry of Housing. The private sector especially real estate developers should take a lead in the provision of residential properties and malls/station precincts as part of the PPP. The real estate developers will have a comparative advantage in leading this task, and they will be able to source capital from the private sector much more efficiently and easily compared to the other partners/developers in this potential arrangement. ${ }^{* *}$ Transport operators have acquired the knowledge, experiences and comparative advantage to manage transport related entities. This acquired expertise does lead to some intrinsic comparative advantage for these players to undertake this task of providing and managing the operation of the rolling stock. Government's role will be to integrate the TTS into the road network, regulate fares and routes to enable fair outcomes as well as facilitating a viable business.

Multifaceted PPP Model (TMPM) due to its emphasis on having three layers of business entities/corporations. This approach of structuring a PPP arrangement is referred to as the "layering approach".

According to Dube \& Chigumira (2010) the rehabilitate-operate and transfer (ROT) type of PPP involves an arrangement that is structured around an already existing infrastructure which is in a dilapidated state. Accordingly, the infrastructure is handed over to the developer who would refurbish, maintain and recondition it. The developer will then operate the infrastructure for a given period to recover its investment costs and get some return on the investment. After the agreed period, the infrastructure is to be transferred to the public authority. This seems as the best PPP arrangement that will suit the City of Bulawayo in order to upgrade almost half of its entire road network that are in a dire state as revealed by City of Bulawayo (2020b: p. 258). The ROT arrangement is suitable 
for the proposed layer one of the TMPM model.

The second layer/level of the TMPM suits the real estate developers and their associated multilateral institutions. These developers will be involved in the construction of the tram station precincts and the residential properties in the surroundings. These constructions are to be designed and built with a purpose to enhance and enable a transition towards achieving transit-oriented developments (TOD) of the corridors as discussed in the study by Ndlovu \& Newman (2020a). The station-based precincts should enable the suburbs to leapfrog developmental and technological barriers (Ndlovu \& Newman, 2020a; Ndlovu \& Newman, 2020). The type and level of development on these precincts should incorporate the construction of the latest technologies such as large scale community based solar charged battery stations, rechargeable battery station for electric vehicles, distributed energy resources (DER) and fully functional malls to give the feel of new "town centres" as expounded by Ndlovu \& Newman (2020a). These town centres or TOD's should be designed with a focus to be the net negative electric cities portrayed by Kennedy et al. (2018). Within this layer, there are various standard PPP arrangements that could be considered for adoption depending on the developers' risk tolerance levels. The ideal PPP arrangement for this layer is the build-own-operate (BOO) arrangement. This arrangement will cover the construction of the malls, commercial and residential properties around the station precincts. Should the city council be interested in providing funding for the construction of some infrastructure then a lease, develop and operate (LDO) arrangement could be considered as well. The estate developers will have to negotiate for partnership with various multilateral institutions such as the superannuation funds and local governments. Under the LDO the private sector/developers could also lease an existing facility and modernise it before assuming operations for a fixed time (Dube \& Chigumira, 2010). The preferred type of PPP in this layer should ideally be structured as a BOO arrangement and thus allow the full potential of the private sector especially property developers' creativity and innovativeness to flourish through building new multi-benefit infrastructure and properties that will lead the City of Bulawayo to be a city of the future, especially in an African context.

The TTS consortium, local transport operators and other public transport related operators will take a lead in this third layer of the proposed TMPM. The TTS consortium will reach out to the currently existing public transport operators and propose a new business corporation venture. Reaching out to the already existing players is crucial in order to reduce resistance which could delay the implementation of the project as was experienced by Sau Paulo, Santiago and Johannesburg in their BRT projects (Willoughby, 2013). The ideal PPP arrangement for this layer of the TMPM model is the build-own-operate-and-transfer scheme (BOOT). The BOOT arrangement has been widely adopted in most countries when it comes to public transportation projects. This arrangement is very flexible; it will allow players on this layer of the TMPM to provide and op- 
erate the trams with little interference from authorities apart from setting regulations for integration into the city's road and transit networks, and the setting of fares. Thus, this layer will need to necessitate public good outcomes as well as enabling the players to recoup their investments costs and returns as quickly as possible.

\section{Discussion and Conclusion}

The two main determinants that enhance success of PPP projects are the bankability of the project, and the capability of the developers. What determines the bankability component is its financial viability, and the determinant of the capability component is having the right partners that are capable to undertake the tasks allocated to them efficiently. Both components are necessary and they depend to a large extent on each other. For example, structuring a partnership that will deliver PPP arrangements requires the allocation of various risks in the project to the right partner who is capable of managing that risk adequately. Allocating the wrong risk to a partner who is not capable of managing it could put the whole PPP arrangement into jeopardy and undermine its bankability. Thus, undertaking a partnership Bankability Assessment and a Capability Evaluation together in a way that recognises the local context depend a lot on determining what each partner should undertake in the project. This study has demonstrated how this combination of the two assessment components depends on a "layering approach" with three different PPP layers which together enable a PP to recognise the strengths of each partner, both government and private developer. This is the TMPM model for the potential TTS project for the City of Bulawayo.

The World Bank Group (WBG) does have various funding programs whereby they can provide loans to PPP project companies via Special Purpose Vehicles (SPVs), and also provide financing to the public sector side of PPPs through sovereign loans. This means with a multilayered PPP model, different partners could utilise different funding arrangements from the WBG. Also, according to Dauskardt \& Ganguly (2020) the IFC Subnational Finance Program of the WBG provides municipal financing directly to municipal and regional governments, and their service entities including for PPPs that provide key subnational infrastructure services. The City of Bulawayo's credit ratings are higher than the country's ratings making it ideal for it to access the IFC municipal loans for its potential PPP projects.

It is also possible to access funding from the UN Climate Fund as the electric transit with solar-based urban regeneration is a model for leap frogging in any emerging city seeking to contribute to reductions in global warming as set out in the Paris Agreement (Masson-Delmotte et al., 2019).

The TMPM model developed in this study is pragmatic and more realistic to enable the adoption of the TTS by the City of Bulawayo. The model also factored in some lessons learnt from some observed PPPs that were successfully implemented in public transportation sectors around the globe especially in South 
American countries. The study also utilised the Polish experience of limiting the capital risk exposure to the players by delineating the project into three small manageable segments or layers. Poland utilised the strategy of segmenting the construction of its A2 Toll Motorway project into smaller construction phases or sizes. In a little deviation to the Polish approach, the TMPM model does split the "vertical" size of the project into smaller sizes thus lowering the capital risk exposure by distributing it to many players while still implementing the whole project. The TMPM structure is ideal for the City of Bulawayo on many fronts, and it can also be easily adopted by other cities that are facing some financial difficulties funding their public infrastructure projects and who would also like to seek other multiple benefits as in this project.

\section{Conflicts of Interest}

The authors declare no conflicts of interest regarding the publication of this paper.

\section{References}

Bhoroma, V. (2020). PPPs Ideal for Self-Financing Infrastructure Projects. Bulawayo24. https://bulawayo24.com/index-id-opinion-sc-columnist-byo-179915.html\#.XlPnLnAh QTU.email

City of Bulawayo (2020a). Corporate Strategy 2020-2024. http://citybyo.co.zw/Downloads/Policies

City of Bulawayo (2020b). Report of Study-Master Plan 2019-2034. http://citybyo.co.zw/Downloads/Policies

Colin Buchanan and Partners (2002). Guide to Contracts and Contracting in the European Union. Report for the European Commission, London: Colin Buchanan and Partners.

Dauskardt, R., \& Ganguly, S. (2020). Designing the African Development Bank's PPP Framework: Whitepaper for Discussion. Abidjan: African Development Bank (AfDB). https://www.afdb.org/sites/default/files/2020/09/15/afdb ppp framework whitepaper. pdf

Dube, C., \& Chigumira, G. (2010). The Scope for Public-Private Partnerships for Infrastructure Development in Zimbabwe.

http://www.zeparu.co.zw/sites/default/files/2018-09/2010Working\%20paper The\%20s cope\%20for\%20PPPs\%20in\%20Zimbabwe Revised\%20Draft.pdf

International Telecommunication Union (ITU) (2014). Speeches by ITU Secretary-General, Dr Hamadoun I. Touré. ITU.

http://www.itu.int/en/osg/Pages/speeches.aspx

Kazunga, O. (2019). Bulawayo Dreams of “Trackless Tram”. Bulawayo. https://www.chronicle.co.zw/bulawayo-dreams-of-trackless-tram

Kennedy, C., Stewart, I. D., Westphal, M. I., Facchini, A., \& Mele, R. (2018). Keeping Global Climate Change within $1.5{ }^{\circ} \mathrm{C}$ through Net Negative Electric Cities. Current Opinion in Environmental Sustainability, 30, 18-25.

https://doi.org/10.1016/j.cosust.2018.02.009

Mandri-Perrott, C., \& Menzies, I. (2010). Private Sector Participation in Light Rail-Light Metro Transit Initiatives. World Bank Group.

https://doi.org/10.1596/978-0-8213-8085-7

http://documents.worldbank.org/curated/en/355141468323976491/Private-sector-parti 
cipation-in-light-rail-light-metro-transit-initiatives

Masson-Delmotte, V., Zhai, P., Pörtner, H.-O., Roberts, D., Skea, J., Shukla, P. R., Pirani, A., Moufouma-Okia, W., Péan, C., Pidcock, R., Connors, S., Matthews, J. B. R., Chen, Y., Zhou, X., Gomis, M. I., Lonnoy, E., Maycock, T., Tignor, M., \& Waterfield, T. (2019). IPCC, 2018: Global Warming of $1.5{ }^{\circ}$ C. An IPCC Special Report on the Impacts of Global Warming of $1.5^{\circ} \mathrm{C}$ above Pre-Industrial Levels and Related Global Greenhouse Gas Emission Pathways, in the Context of Strengthening the Global Response to the Threat of Climate Change, Sustainable Development, and Efforts to Eradicate Poverty.

Mbiba, B., \& Ndubiwa, M. (2008). Decent Work in Construction and the Role of Local Authorities: The Case of Bulawayo City, Zimbabwe. http://eprints.lse.ac.uk/3015/

Meidutē, I., \& Paliulis, N. K. (2011). Feasibility Study of Public-Private Partnership. International Journal of Strategic Property Management, 15, 257-274.

https://doi.org/10.3846/1648715X.2011.617860

Ndlovu, V., \& Newman, P. (2020). Leapfrog Technology and How It Applies to Trackless Tram. Journal of Transportation Technologies, 10, 198-213. https://doi.org/10.4236/jtts.2020.103013

Ndlovu, V., \& Newman, P. (2020a). Designing a Transit Oriented Development with a Trackless Tram System-Case Study Bulawayo. Journal of Urban Planning and Development.

Ndlovu, V., \& Newman, P. (2020b). The Public-Private Partnership Procurement Approach-Zimbabwe Case. The World Bank Research Observer Journal.

Ndlovu, V., Newman, P., \& Sidambe, M. (2020). Prioritisation and Localisation of Sustainable Development Goals (SDGs): Challenges and Opportunities for Bulawayo. Journal of Sustainable Development, 13, 104-118. https://doi.org/10.5539/jsd.v13n5p104

Newman, P., Davies-Slate, S., \& Jones, E. (2018). The Entrepreneur Rail Model: Funding Urban Rail through Majority Private Investment in Urban Regeneration. Research in Transportation Economics, 67, 19-28. https://doi.org/10.1016/j.retrec.2017.04.005

Newman, P., Hargroves, K., Davies-Slate, S., Conley, D., Verschuer, M., Mouritz, M., \& Yangka, D. (2019). The Trackless Tram: Is It the Transit and City Shaping Catalyst We Have Been Waiting for? Journal of Transportation Technologies, 9, 31-55. https://doi.org/10.4236/jtts.2019.91003

Newman, P., Mouritz, M., Davies-Slate, S., Jones, E., Hargroves, K., Sharma, R., \& Adams, D. (2018). Delivering Integrated Transit, Land Development and Finance-A Guide and Manual with Application to Trackless Trams. Australia's Sustainable Built Environment National Research Centre (SBEnrc). https://sbenrc.com.au/app/uploads/2018/10/TRACKLESS-TRAMS-MANUAL-GUIDE email.pdf

Suzuki, H., Murakami, J., Hong, Y.-H., \& Tamayose, B. (2015). Financing Transit-Oriented Development with Land Values: Adapting Land Value Capture in Developing Countries. Washington DC: The World Bank. https://doi.org/10.1596/978-1-4648-0149-5

Willoughby, C. (2013). How Much Can Public Private Partnership Really Do for Urban Transport in Developing Countries? Research in Transportation Economics, 40, 34-55. https://doi.org/10.1016/j.retrec.2012.06.038

Zaaijer, M. (1998). Urban Economic Restructuring and Local Institutional Response: The Case of Bulawayo, Zimbabwe. 